\title{
Figural a Flexibility Test for Improving Creative Thinking in an Arabic Learning Environment
}

\author{
A Saudi Arabia-Based Case Study
}

\author{
Nahla Aljojo \\ Faculty of Computing and Information Technology, \\ Information Systems Department, \\ King Abdulaziz University, \\ Jeddah, Saudi Arabia
}

\begin{abstract}
The capability of graduates to be flexible in the face of rapidly altering situations is an increasingly crucial requirement that teachers should be conscious of, given that persistent development and technological progress are characteristic of contemporary life. Proficiency for learning and cognitive abilities are two areas in which learners need to acquire knowledge. Cognitive spatial ability has various dynamics, the assessment of which can be undertaken through numerous techniques. The major objectives of this paper are to develop a web-based system for measuring adult cognitive ability within an Arabic learning environment, in addition to enhancing their creative thinking and learning capabilities through utilising the kit of factor referenced cognitive tests, devised by Ekstrom et al. (1976). The web-based system will focus on the figural flexibility test (Toothpicks test - planning patterns - storage test). Each test has its own objective with regard to assisting with the measurement of people's creative ability in different ways, as a means of enhancing creative thinking and learning. Prior to constructing the figural flexibility test system, we are going to distribute a questionnaire in order to assess and examine certain crucial aspects, to inform the construction of our system. The questionnaires were distributed to university students in the Faculty of Computing and Information Technology (FCIT), in addition to random distribution via email and social media, namely, Facebook, Twitter and WhatsApp. Over 500 questionnaires were distributed with 400 responses received. The objective was to assess the new system's feasibility, as well as to design a system that meets the user's requirements. As a result of the questionnaire, $77 \%$ of people were found to believe that creating a web-based system can assist students with developing their creative thinking and learning abilities.
\end{abstract}

Keywords-Creative thinking; kit of factor referenced cognitive tests; students; toothpicks; planning patterns; storage test; cognitive abilities

\section{INTRODUCTION}

Some of the primary definitions of relevance to this paper include:

Cognitive training: As Coutinho [4] explained, memory, attention and problem-solving skills and various other cognitive functioning capabilities are reviewed and practice through engagement in such training.

Working memory: This term refers to a brain system that offers impermanent data banking and handling, permitting complicated cognitive tasks such as language comprehension, learning and reasoning to be completed [1].

Cognitive abilities: These govern a spectrum of tasks from the most basic to the incredibly complicated, based on the capabilities of the brain. As opposed to being concerned with information itself, it is the means through which one focuses, tackles challenges, recalls and learns which cognitive ability is relevant to. Even the task of holding a phone conversation requires various abilities: conversing appropriately with the other individual and interpreting their voice manner necessitates social abilities; comprehension of language and discussion requires language ability, holding the telephone draws on motor abilities; responding to a call necessitates choice making, while hearing the initial call requires perception. Mental functions or cognitive abilities are founded on particular neuronal networks. For example, memory skills draw largely on temporal lobe and frontal lobe areas, the latter of which is behind the forehead [11].

According to the particularly pertinent aspects that the psychology specialist identifies in relation to reasoning ability, an array of questions in relation to cognitive ability can be applied in psychometric analysis. Mechanical, spatial, abstract, verbal and numerical questions can be classified as part of psychometric assessments. Psychometric assessments may be narrowly focused on a particular classification of questions, while different assessments will be broader. As Psychometric [6], [13], [14] explained, data that is conveyed in words and the ability to comprehend it will be the sole focus of a verbal reasoning ability assessment.

Language, calculation, problem resolution, visual-spatial awareness, concentration, memory and various other abilities can be quantified and analysed as thinking or cognitive skills, through cognitive ability assessments. Drawing on Michelon [10], [11], Table 1 outlines the major brain activities associated with thought, while certain puzzles and tests to train and hone one's cognitive skills are also identified. 
TABLE I. COGNITIVE ABILITIES AND THE BRAIN's FunCtions

\begin{tabular}{|c|c|}
\hline $\begin{array}{l}\text { Cognitive Ability/Brain } \\
\text { Function }\end{array}$ & Skills involved \\
\hline Perception & $\begin{array}{l}\text { Recognition and interpreta-tion of } \\
\text { sensory stimuli, for example smell, } \\
\text { touch and hearing. } \\
\text { Brain puzzles: } \\
\text { O Is this a circle? } \\
\text { Catch the number }\end{array}$ \\
\hline Attention & $\begin{array}{l}\text { The ability to sustain con-centration on } \\
\text { a particular object, action or thought. } \\
\text { The ability to manage peting demands } \\
\text { within our environment. } \\
\text { Brain puzzles: } \\
\circ \text { Count the letters } \\
\circ \text { Spot the differences } \\
\bigcirc \text { Awareness test }\end{array}$ \\
\hline Memory & $\begin{array}{l}\text { Short-term/ working memory (limited } \\
\text { storage). Long-term memory (unlimited } \\
\text { storage). }\end{array}$ \\
\hline Motor skills & $\begin{array}{l}\text { The ability to mobilise our muscles and } \\
\text { bodies. The ability to manipulate } \\
\text { objects. } \\
\text { Brain puzzles: } \\
\text { Tap your right hand on the } \\
\text { table. Consecutively, make a } \\
\text { circular movement with your } \\
\text { left hand, in the motion of } \\
\text { cleaning the table. } \\
\text { Switch hands }\end{array}$ \\
\hline Language & $\begin{array}{l}\text { Skills permitting us to translate sounds } \\
\text { into words, thus generating verbal } \\
\text { output. } \\
\text { Brain puzzles: } \\
\text { O Words associations } \\
\circ \quad \text { What is the word? }\end{array}$ \\
\hline Visual and Spatial Processing & $\begin{array}{l}\text { The ability to process incoming visual } \\
\text { stimuli. The ability to comprehend } \\
\text { spatial relationships between objects. } \\
\text { The ability to visualize images and } \\
\text { scenarios. } \\
\text { Brain puzzles: } \\
\text { Build the box } \\
\text { Which piece is missing? }\end{array}$ \\
\hline
\end{tabular}

This paper's major objectives are to develop a web-based system for measuring adult cognitive ability, while also seeking to enhance their abilities for creative thinking and learning proficiency, by focusing on the figural flexibility test (Toothpicks Test - Planning Patterns - Storage test).

\section{Kit OF FACtOR REFERENCED COGNITIVE TESTS}

The kit of factor referenced cognitive tests is unique among multiple aptitude measures, due to it being intended solely for research, while also being based on an amalgamation of factor analysis and information processing theory. This version of the kit comprises of two to three measures, each consisting of 23 basic cognitive factors covering dimensions including reasoning, verbal ability, spatial ability, memory and fluency (see Table 2). The kit is supported on a large body of research stretching back to the 1940 s, thus strengthening its reliability and validity [5].
TABLE II. MARKER ASSESSMENTS FOR 23 APTITUDE FACTORS

\begin{tabular}{|c|c|}
\hline \begin{tabular}{ll}
\multicolumn{3}{l}{ Closure, Flexibility of } \\
1. & Hidden figures assessment \\
2. & Hidden patterns assessment \\
3. & Copying assessment \\
\end{tabular} & \begin{tabular}{ll}
\multicolumn{3}{l}{ Memory, Visual } \\
1. & Shape memory assessment \\
2. & Building memory \\
3. & Map memory \\
\end{tabular} \\
\hline $\begin{array}{cl}\text { Closure, speed of } \\
\text { 1. } & \text { Gestalt completion } \\
& \text { assessment } \\
\text { 2. } & \text { Concealed words assessment } \\
\text { 3. } & \text { Snowy pictures }\end{array}$ & $\begin{array}{cl}\text { Number } \\
\text { 1. } & \text { Addition assessment } \\
\text { 2. } & \text { Division assessment } \\
\text { 3. } & \text { Subtraction \& Multiplication } \\
& \begin{array}{l}\text { assessment } \\
\text { 4. }\end{array} \\
& \begin{array}{l}\text { Addition \& subtraction } \\
\text { correction }\end{array} \\
\end{array}$ \\
\hline $\begin{array}{cl}\text { Closure, verbal } \\
\text { 1. } & \text { Scrambled words } \\
\text { 2. } & \text { Hidden words } \\
\text { 3. } & \text { Incomplete words }\end{array}$ & $\begin{array}{cl}\text { Perceptual speed } \\
\text { 1. } & \text { Finding A's assessment } \\
\text { 2. } & \text { Number comparison } \\
& \text { assessment } \\
\text { 3. } & \text { Identical pictures assessment } \\
\end{array}$ \\
\hline 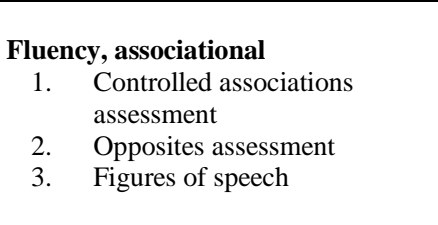 & \begin{aligned} & \multicolumn{2}{l}{ Reasoning, general } \\
& 1. Arithmetic aptitude \\
& assessment \\
& 2. Mathematics aptitude \\
& assessment \\
& 3. $\begin{array}{l}\text { Necessary arithmetic } \\
\text { operations assessment }\end{array}\end{aligned}$ \\
\hline 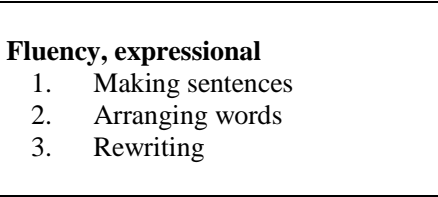 & $\begin{array}{cl}\text { Reasoning, logical } \\
\text { 1. } & \text { Nonsense syllogisms } \\
& \text { assessment } \\
\text { 2. } & \text { Diagramming relationship } \\
\text { 3. } & \text { Inference assessment } \\
\text { 4. } & \text { Deciphering languages } \\
\end{array}$ \\
\hline $\begin{array}{ll}\text { Fluency, figural } \\
\text { 1. } & \text { Ornamentation assessment } \\
\text { 2. } & \text { Elaboration assessment } \\
\text { 3. } & \text { Symbols assessment } \\
\end{array}$ & $\begin{array}{cl}\text { Spatial orientation } \\
\text { 1. } & \text { Card rotations assessment } \\
\text { 2. } & \text { Cube comparisons } \\
& \text { assessment } \\
\end{array}$ \\
\hline $\begin{array}{l}\text { Fluency, ideational } \\
\text { 1. } \quad \text { Topics assessment } \\
\text { 2. Theme assessment } \\
\text { 3. } \quad \text { Thing categories assessment }\end{array}$ & 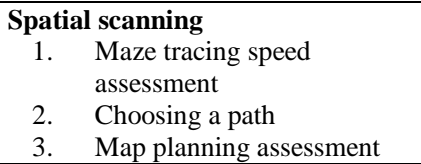 \\
\hline $\begin{array}{l}\text { Fluency, word } \\
\text { 1. Word endings assessment } \\
\text { 2. Word beginnings assessment } \\
\text { 3. Word beginnings and endings } \\
\text { assessment }\end{array}$ & \begin{tabular}{cl}
\multicolumn{2}{l}{ Verbal comprehension } \\
1. & Vocabulary assessment 1 \\
2. & Vocabulary assessment 2 \\
3. & Extended range Vocabulary \\
4. & Adsessment \\
& $\begin{array}{l}\text { advanced Vocabulary } \\
\text { 5. }\end{array}$ \\
& $\begin{array}{l}\text { Advanced Vocabulary } \\
\text { assessment 2 }\end{array}$ \\
\end{tabular} \\
\hline $\begin{array}{ll}\text { Induction } \\
\text { 1. } & \text { Letter sets assessment } \\
\text { 2. } & \text { Locations assessment } \\
\text { 3. } & \text { Figure classification }\end{array}$ & $\begin{array}{cl}\text { Visualization } \\
\text { 1. } & \text { From board assessment } \\
\text { 2. } & \text { Paper folding assessment } \\
\text { 3. } & \text { Surface development } \\
& \text { assessment } \\
\end{array}$ \\
\hline $\begin{array}{l}\text { Integrative processes } \\
\text { 1. } \quad \text { Calendar assessment } \\
\text { 2. } \quad \text { Following directions }\end{array}$ & $\begin{array}{cl}\text { Flexibility, figural } \\
\text { 1. } & \text { Toothpicks assessment } \\
\text { 2. } & \text { Planning patterns } \\
\text { 3. } & \text { Storage assessment }\end{array}$ \\
\hline $\begin{array}{l}\text { Memory, associative } \\
\text { 1. } \quad \text { Picture-Number assessment } \\
\text { 2. Object-Number assessment } \\
\text { 3. } \\
\text { First \& last names assessment }\end{array}$ & $\begin{array}{cl}\text { Flexibility of use } \\
\text { 1. } & \text { Combining objects } \\
\text { 2. } & \text { Substitute uses } \\
\text { 3. } & \text { Making groups } \\
\text { 4. } & \text { Different uses } \\
\end{array}$ \\
\hline \begin{aligned} & \multicolumn{2}{l}{ Memory span } \\
& 1. Auditory number span \\
& assessment \\
& 2. Visual number span \\
& assessment \\
& 3. $\begin{array}{l}\text { Auditory letter span } \\
\text { assessment }\end{array} \\
&\end{aligned}$ & \\
\hline
\end{tabular}


For factor analytic research, a tool permitting analysts to assess particular aptitude variables is provided by the cognitive assessments based around a set of 72 factors. The ability to contrast particular variables in a valid manner, with understanding simplified, is the objective of such an assessment. Nevertheless, across various kinds of investigation, the process of identification of comparable factors across studies may be made more objective, through incorporating marker tests for factors that may be anticipated to appear or for factors that a researcher wishes to isolate from other domains of interest [5].

\section{A. Figural Flexibility Test}

The figural flexibility assessment provides the ability to alter the set order, generating new and alternative solutions to figural problems. In the 1963 edition of this kit and through the work done in Guilford's laboratory, this factor was called figural adaptive flexibility. Cattell [3] refers to it as adaptive flexibility, because the existence of this factor has been demonstrated only with flexibility material, while there appear to be other types of flexibility restricted to non-figural material, therefore the new term was selected.

Both Royce [16] and Cattell [3] have stated that figural adaptive flexibility can be amalgamated with several other abilities to produce a second-order visualisation factor. Carroll [2] proposed that figural adaptive flexibility necessitates the equivalent process, imaging a figure in relation to a surrounding visual representation field, similar to flexibility of closure; however, it also entails a search for relevant hypotheses in long-term memory and the performance of serial operations. In accordance with Ekstrom et al. [5], [8], the figural flexibility test for measuring cognitive spatial ability can be outlined as follows:

\section{1) Toothpicks Test}

In this assessment, the individual will be asked to produce outlines of different squares using toothpicks. The participant will be shown a pattern of squares and then be asked to alter it by removing some of the toothpicks. Subsequently, they can show which toothpicks should be removed by drawing a short line on them. Consider the example below (see Fig. 1):
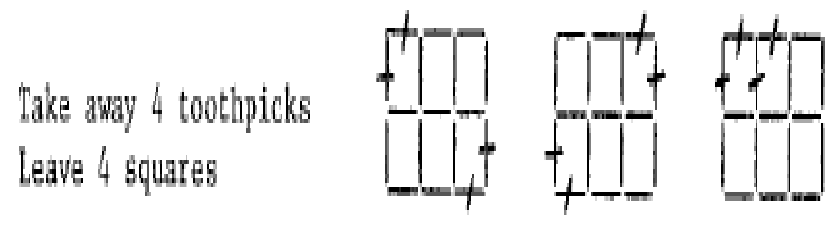

Fig. 1. Toothpicks test example.

\section{2) Planning Pattern Testing}

In this assessment, the participant is asked to plan how certain figures may be arranged onto a group of dots. The respondent will be asked to consider as many different ways that they possibly can to arrange the figures. Consider the example below, where three possible solutions to the problem are illustrated on the right (see Fig. 2).

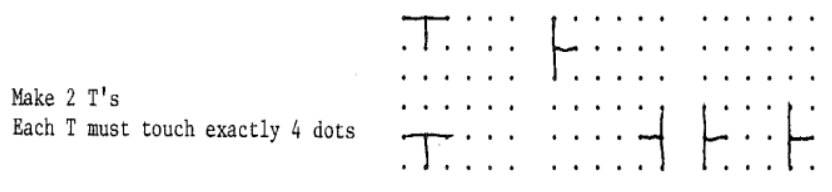

Fig. 2. Planning pattern test example.

\section{3) Storage Test}

In this assessment, the participant will be asked to plan objects that may be stored within a given space. The respondent will be asked to consider as many different ways as possible for the objects to be arranged in this space.

How many different ways may 4 boxes, as displayed in Fig. 3 on the left below, be stored in the container shown on the right? The numbers on the sides of the boxes and the dotted lines are to assist the viewer in comparing the sizes.
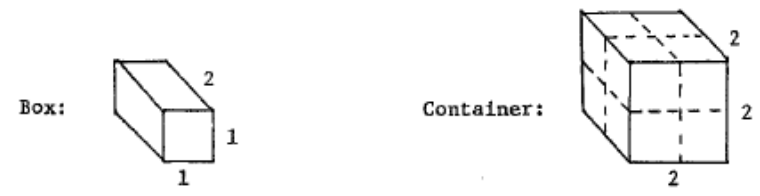

Fig. 3. Storage test example.

\section{LITERATURE REVIEW}

For the purpose of this research, it is essential for a brief background and historical account to be provided concerning some theories relating to cognitive tests in adulthood, as a means of enhancing creative thinking and learning abilities.

\section{A. Virginia State University, Department of Technology}

A 3-dimensional rotation test was utilised in this research, which sought to assess engineering students' cognitive spatial ability, who were based at Virginia State University at the time. Such tests are regularly adopted to assess engineering students' cognitive spatial abilities, for example Vandenberg and Kuse's [18] mental rotation test, or Guay's [9] Purdue spatial visualisation assessment.

Nevertheless, as N.E. Study [12] explained, science, technology, engineering and mathematics (STEM) subject assignments, issue resolution, engineering planning and a host of other aspects' effective undertaking, often rely upon myriad spatial ability skills to formulate the mental models that are required, thus learners' capacity to mentally orientate objects in three dimensions are just one requisite skill.

\section{B. The Relationship between Rigidity-Flexibility and Cognitive Abilities in Adulthood}

Adult cognitive abilities and rigidity-flexibility's physical correlation is the focus of this research investigation. The justification for this is that as one enters later life from their earlier adulthood, variations in cognitive decline across people may be explicated on the basis of rigidity-flexibility, it having been posited as a character variable of significant importance. In accordance with Schaie et al. [17], 1,628 individuals aged between 22-95 years comprised the research sample. 
Rigidity-flexibility is a personality dimension that has been repeatedly associated with the ability to estimate cognitive decline during advanced maturity. Nevertheless, the multidimensional character of the factor of rigidity-flexibility is also acknowledged. Three rigidity-flexibility dimensions were investigated by Schaie et al. [17] in relation to crossgeneration and age alteration variations. Certain rigidityflexibility aspects were characterised by greater rigidity. Additionally, the researchers determined that younger subjects were advantaged by beneficial cohort impacts.

\section{Playing an Action Video Game Reduces Gender Differences in Spatial Cognition}

Mental rotation ability- a spatial cognition procedure of a higher order- as well as spatial focus, are both characterised by a discrepancy of ability between genders, however the research has indicated that this discrepancy may be virtually eradicated through participation in the video game. Females were found to be advantaged to a greater degree than males with regard to cognitive rotation and spatial focus ability, skills that increased considerably following participation in the action computer game of just 10 hours. No enhancement in capability was seen for the control participants who were using the non-action game. As Feng et al. [7] proposed, the process of encouraging both females and males to enter engineering science and mathematics careers may be informed by the outcomes of this research, due to the crucial role of refined spatial capabilities.

\section{METHODOLOGY}

The overall methodology for this research comprise of several stages:

Stage 1: Reviewing the existing literature and previous work concerned with the design of cognitive spatial ability, in order to improve creative thinking.

Stage 2: Interview

An interview was conducted with a Psychological Counsellor from the Brain Training and Psychological Counselling Office, who possesses expertise in the field of cognitive spatial ability assessments and special needs (learning difficulties) in particular.

Stage 3: Questionnaires:

The questionnaires were distributed among university students in the FCIT, in addition to random distribution via email and social media, namely Facebook, Twitter and WhatsApp. Over 500 questionnaires were distributed, with 400 responses obtained. The objective was to assess the feasibility of the original system, in addition to designing a system reflecting the users' requirements.

\section{Stage 4: Implementation}

Installation, configuration, running, testing and the introduction of essential alterations to original software and hardware, as a means of ensuring efficient running of the system, can be encapsulated in the procedures of implementation.
During this stage, all of the planned activities were implemented. The implementation process continues until the production system is operating in accordance with the defined requirements [15]. Furthermore, this phase will incorporate the tools utilised to build our system, including the hardware, software, programming languages and system walkthrough. Drawing on the discussion with certain psychology specialists, the implementation of this process was reliant upon their perspective of how the test would be practically implemented, in addition to how the website would provide instructive information supporting users and simplifying their requirements. Therefore, we focused our effort on being as helpful as possible, for example making the website contents as simple and straightforward to use as possible.

\section{RESUlTS AND DATA ANALYSIS}

The questionnaire results are presented in Table 3. 400 participants responded, characterised by different ages and educational levels.

TABLE III. PARTICIPANTS’ RESPONSES TO THE QUESTIONNAIRE

\begin{tabular}{|c|c|c|c|c|}
\hline \multirow{2}{*}{\multicolumn{2}{|c|}{ QUESTIONS }} & \multicolumn{3}{|l|}{ Answer } \\
\hline & & $Y E S$ & $\mathrm{NO}$ & Sort of \\
\hline 1) & $\begin{array}{l}\text { Do you know how to use } \\
\text { a computer? }\end{array}$ & $56.5 \%$ & $5.4 \%$ & $38.1 \%$ \\
\hline 2) & $\begin{array}{l}\text { Do you know how to use } \\
\text { the Internet? }\end{array}$ & $76.2 \%$ & $5.4 \%$ & $18.4 \%$ \\
\hline 3) & $\begin{array}{l}\text { Do you have any } \\
\text { understanding of creative } \\
\text { thinking? }\end{array}$ & $21.8 \%$ & $39 \%$ & $39.2 \%$ \\
\hline 4) & $\begin{array}{l}\text { Have you taken a test to } \\
\text { measure your creative } \\
\text { thinking before? }\end{array}$ & $37.8 \%$ & $62.2 \%$ & \\
\hline 5) & $\begin{array}{l}\text { Do you support the idea } \\
\text { of creating a website to } \\
\text { measure creative } \\
\text { thinking? }\end{array}$ & $85.8 \%$ & $3.7 \%$ & $10.5 \%$ \\
\hline 6) & $\begin{array}{l}\text { Do you think that this test } \\
\text { will help students to } \\
\text { develop their creative } \\
\text { thinking? }\end{array}$ & $77 \%$ & $2.5 \%$ & $20.5 \%$ \\
\hline 7) & $\begin{array}{l}\text { Do you support the idea } \\
\text { of measuring creative } \\
\text { thinking for each student } \\
\text { when they join the } \\
\text { university or school, in } \\
\text { order to increase and } \\
\text { improve the student's } \\
\text { academic level? }\end{array}$ & $72 \%$ & $8 \%$ & $20 \%$ \\
\hline \multirow[t]{2}{*}{ 8) } & \multirow{2}{*}{$\begin{array}{l}\text { Do you prefer the } \\
\text { implementation of this } \\
\text { idea to be via a website or } \\
\text { mobile application? }\end{array}$} & Mobile & \multicolumn{2}{|l|}{ Website } \\
\hline & & $52 \%$ & \multicolumn{2}{|l|}{$48 \%$} \\
\hline \multirow[t]{2}{*}{ 9) } & \multirow{2}{*}{$\begin{array}{l}\text { Which language do you } \\
\text { prefer for the website? }\end{array}$} & Arabic & English & $\begin{array}{l}\text { Arabic \& } \\
\text { English }\end{array}$ \\
\hline & & $20 \%$ & $3 \%$ & $77 \%$ \\
\hline
\end{tabular}




\section{DESIGN AND IMPLEMENTATION OF WEB-BASED SYSTEMS}

The web-based system is connected to an external database, which we have established using the WAMP Server. We used MYSQL as a means of creating the database, while we utilised HTML, CSS, and Java script programs in order to design and develop the website. Furthermore, we adopted Notepad++ to write the PHP codes, which work as a mediator between the database and the website in the process of sending and receiving instructions. Additionally, we utilised Photoshop to design the logo.

\section{A. Web-based System Design}

The home of the web-based system is presented in Fig. 4. The home page displays the major menu that comprises of certain features, such as 'Home', 'About us', 'Cognitive test', 'Quick games', 'Help', 'Feedback' and 'Contact us'. Moreover, an introduction to the test is provided, alongside some movable pictures.

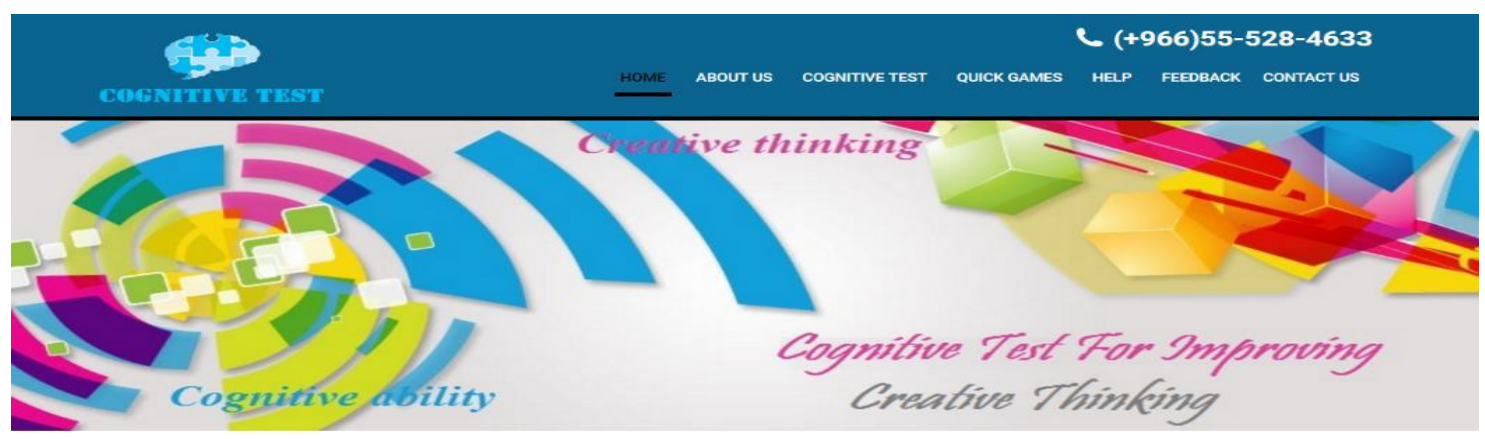

\section{Introduction}

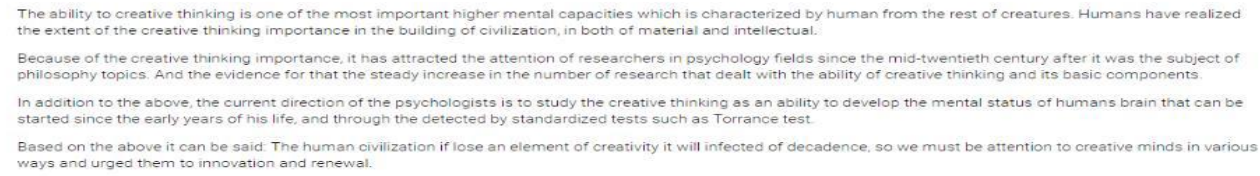

\section{Gallery}
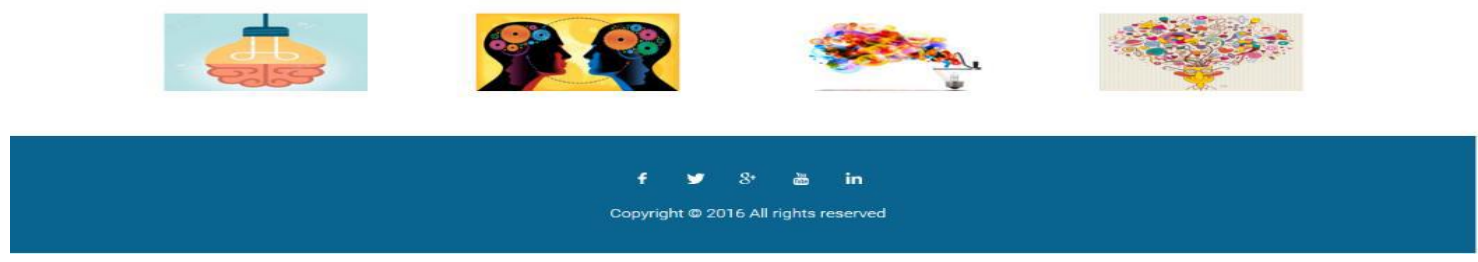

Fig. 4. Home page.
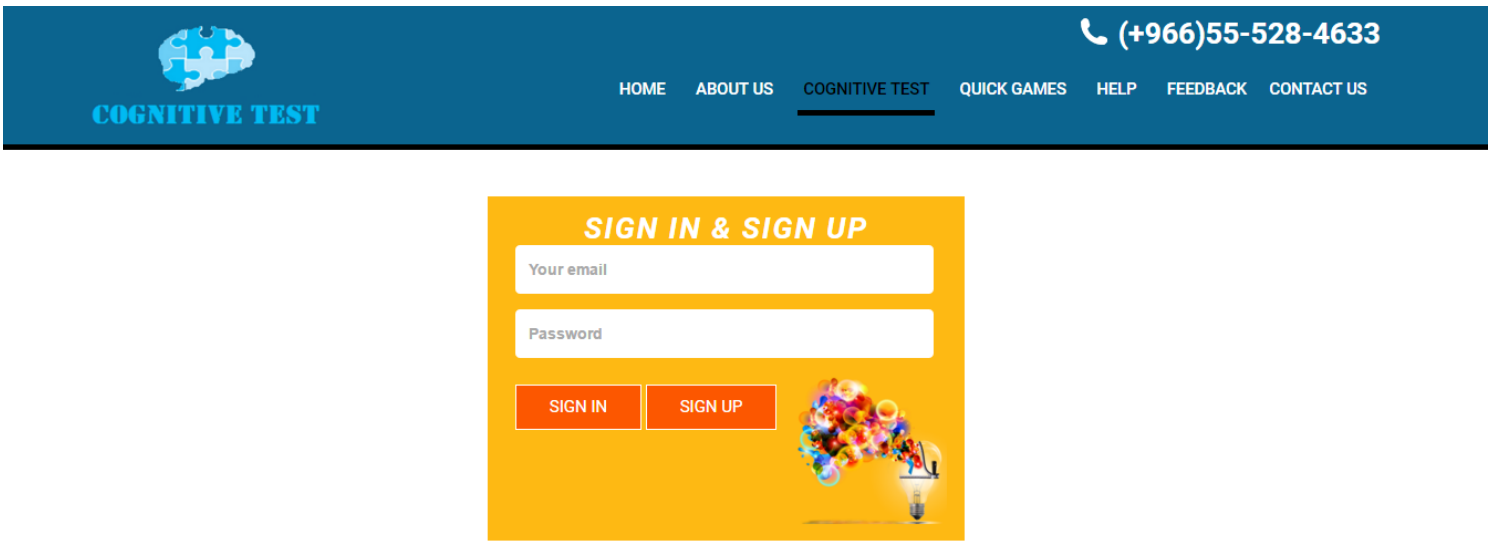

\section{f s $^{+}$in in}

Fig. 5. Cognitive test page. 
The site is divided into three main areas: the top area, the content area and the bottom area.

The top area: This displays the main menu and the banner.

The content area: This displays the website content, namely the text, pictures, forms and the test.

The bottom area: This contains the copyright regarding the website, alongside the social media links.

\section{1) Cognitive test}

This page provides a brief description and definition of cognitive ability, while also displaying the test logo and the sign-in form, as illustrated by Fig. 5.

\section{2) Sign up}

On this page, the web-based system visitor can fill in the registration form, creating a new account that permits entry to the system where they are able to take the test, as presented in Fig. 6.
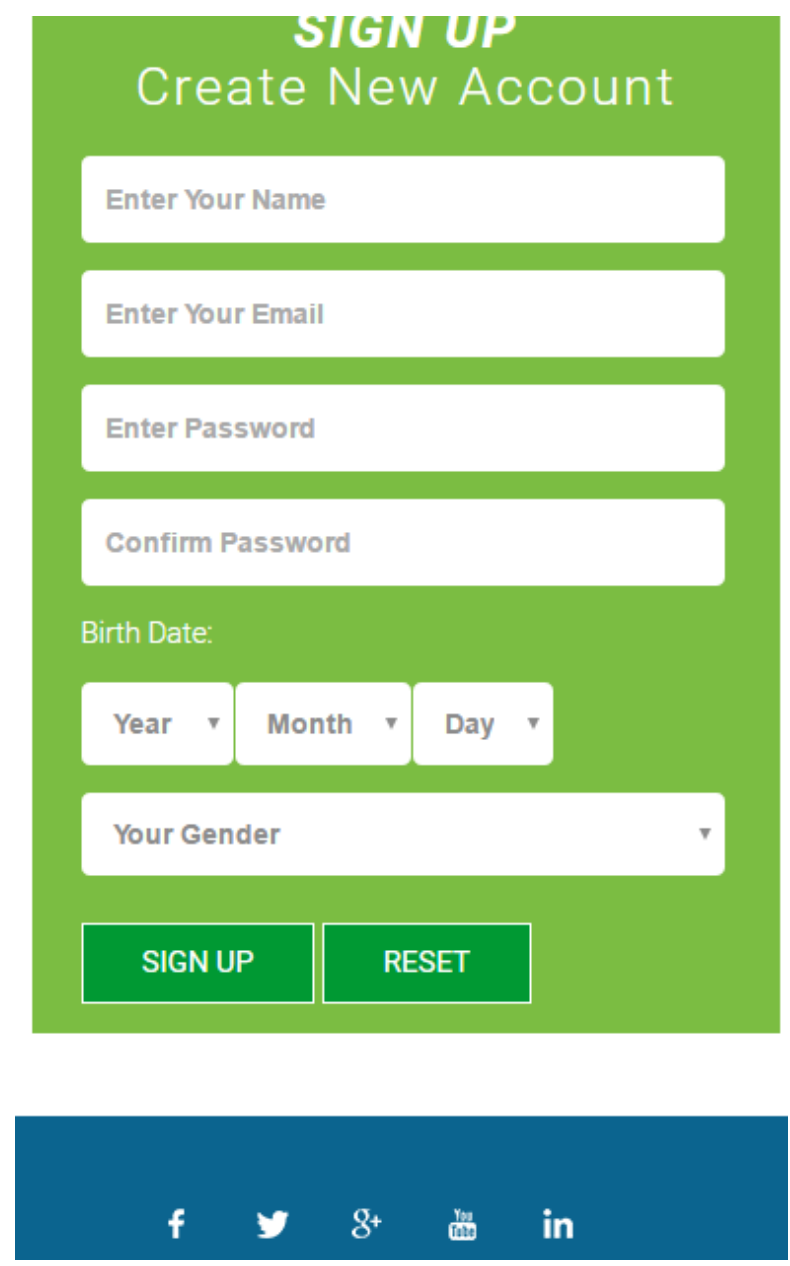

Fig. 6. Sign up page.

\section{3) Toothpicks Test}

When the user wishes to initiate the test, they can select either the English version or the Arabic version. Once they have chosen the version of the test that they want, it will begin (see Fig. 7 and 8).

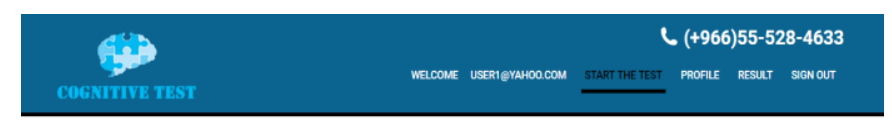

\section{Start The Test}
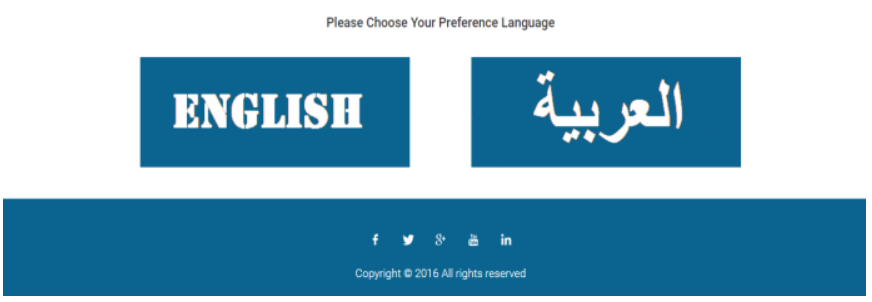

Fig. 7. Test page.

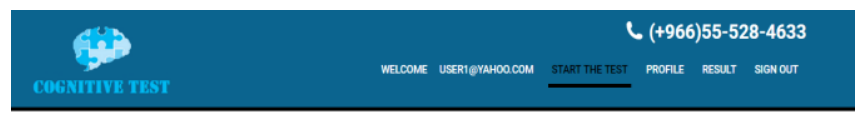

Toothpicks Test

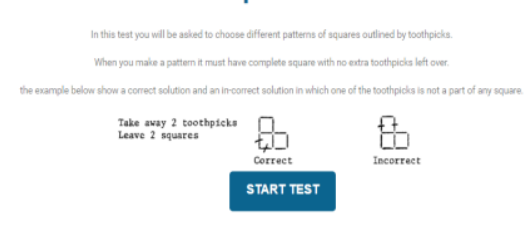

Fig. 8. Toothpicks test.

4) Result

As illustrated in Fig. 9, this page displays the user's last result, enabling them to review it in any point.
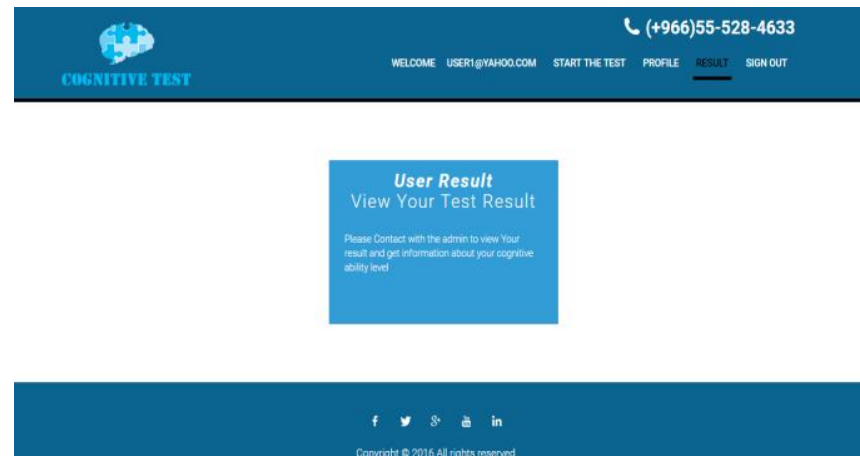

Fig. 9. Results page.

\section{CONCLUSION}

This paper handles a crucial subject, which is an assessment of the ability to engage in creative thinking in relation to various psychological components. Ultimately, the interaction and overlap between these components enhances the ability for creative thinking, which is one of the most crucial higher cognitive abilities that humans possess, providing them with such capabilities as sensitivity to problems, fluency, flexibility, originality, details or enlargement. The major objective of this paper is to create a Web-based system measuring adults' cognitive ability, which enables them to enhance their ability for creative thinking. Furthermore a Web-based system was devised that provided 
certain advices and guidance, based on the information provided by certain psychology specialists.

\section{REFERENCES}

[1] Baddeley, A. D., Allen, R. J., \& Hitch, G. J. (2011). Binding in visual working memory: The role of the episodic buffer. Neuropsychologia, 49(6), 1393-1400.

[2] Carroll, J. B. (1974). Psychometric Tests as Cognitive Tasks: A New'Structure of Intellect' (No. ETS-RB-74-16). EDUCATIONAL TESTING SERVICE PRINCETON NJ.

[3] Cattell, R. B. (1971). Abilities: Their structure, growth, and action. Boston: Houghton Mifflin

[4] Coutinho, J., de Bruijn, S. F., Deveber, G., \& Stam, J. (2011) Anticoagulation for cerebral venous sinus thrombosis. The Cochrane Library

[5] Ekstrom, R. B., French, J. W., Harman, H. H., \& Dermen, D. (1976) Manual for kit of factor-referenced cognitive tests. Princeton, NJ Educational testing service.

[6] Eliot, J., \& Czarnolewski, M. (1999). A composite Gestalt completion test. Perceptual and motor skills, 89(1), 294-300.

[7] Feng, J., Spence, I., \& Pratt, J. (2007). Playing an action video game reduces gender differences in spatial cognition. Psychological science, $18(10), 850-855$.

[8] French, J. W., Ekstrom, R. B., \& Price, L. A. (1963). Manual for kit of reference tests for cognitive factors (revised 1963). EDUCATIONAL TESTING SERVICE PRINCETON
[9] Guay, R. (1976). Purdue Spatial Vizualization Test. Educational testing service.

[10] Likert, R., Quasha, W. (1995). Revised Minnesota paper from board test manual $\left(2^{\text {nd }}\right)$ San Antonio TX: The Psychological Corporation.

[11] Michelon, P. (2006) What are cognitive abilities and skills, and how to boost them? Sharpbrains.com [Online] Available at: www.sharpbrains.com/blog/2006/12/18/what-are-cognitive-abilities/ [Accessed: 10 January 2015]

[12] N. E. Study. Department of Technology. Virginia State University. (2012). An overview of tests of cognitive spatial ability.

[13] Psychometric testing, (2013), Cognitive ability test. [Online] Available at: http://www.psychometric-success.com/faq/faq-cognitive-abilitytest.htm [Accessed 2013].

[14] Raven, J. C. (1938). Progressive matrices: A perceptual test of intelligence. London: HK Lewis.

[15] Rouse, M., 2015. Techtarget. [Online] Available at: http://searchcrm.techtarget.com/definition/implementation [Accessed Feb 2016].

[16] Royce, J. R. (1973). Multivariate analysis and psychological theory.

[17] Schaie, K. W., Dutta, R., \& Willis, S. L. (1991). Relationship between rigidity-flexibility and cognitive abilities in adulthood. Psychology and aging, 6(3), 371.

[18] Vandenberg, S. G., \& Kuse, A. R. (1978). Mental rotations, a group test of three-dimensional spatial visualization. Perceptual and motor skills, 47(2), 599-604. 